\title{
CLINICAL BENEFITS OF ENDOSCOPIC VEN HARVESTING IN PATIENTS WITH RISK FACTORS FOR SAPHENECTOMY WOUND INFECTIONS UNDERGOING CORONARY ARTERY BYPASS GRAFTING
}

Phillip A. Carpino, PA, MHP

Kamal R. Khabbaz, MD

Robert M. Bojar, MD

Hassan Rastegar, MD

Kenneth G. Warner, MD

Richard E. Murphy, PA, MBA

Douglas D. Payne, MD

Sponsor: Benedict D. T. Daly, MD
Objective: The influence of endoscopic harvesting techniques on the prevalence of leg-wound complications after coronary artery bypass grafting remains to be defined for patients at high risk for the development of wound infections. Methods: Among 1473 patients undergoing coronary artery bypass grafting who had the saphenous vein harvested by either a continuous incision or skip incisions leaving intact skin bridges, we determined the prevalence of wound infections to be $9.6 \%$. The following variables were entered into logistic regression analysis to identify significant risk factors that might be predictive of wound infection: diabetes, peripheral vascular disease, obesity, renal failure, steroid use, age, sex, and type of closure. We then prospectively randomized 132 patients found to be at high risk of wound infection to either endoscopic vein harvesting or a continuous open incision. Results: Univariate analysis showed female sex $(P=.04)$, diabetes $(P<.001)$, and obesity $(P$ $<.001)$ to be predictors of wound infection. In a multivariate model diabetes $(P=.02)$ and obesity $(P=.001)$ were independent predictors. In patients at high risk, the prevalence of wound infection was $4.5 \%$ for the endoscopic group versus $20 \%$ for the open group $(P=.01)$. Vein procurement time was greater in the endoscopic group (65 minutes vs 32 minutes, $P<.001)$, as was the number of vein repairs required $(2.5 \mathrm{vs}$ $0.6, P<.001)$. Conclusion: The use of endoscopic vein harvesting decreases the prevalence of postoperative leg-wound infections in high-risk patients with diabetes and obesity. Whether this translates into an economic benefit that justifies the additional cost of that technology requires further analysis. (J Thorac Cardiovasc Surg 2000;119:69-76)
$\mathrm{D}$ espite the extensive use of arterial conduits to improve long-term graft patency, most patients undergoing multivessel coronary artery bypass grafting (CABG) still receive several saphenous vein bypass grafts. Common leg-wound complications, which include cellulitis, lymphangitis, purulent drainage, wound breakdown with eschar formation, and fat necrosis, have been reported to occur in $1.5 \%$ to $24 \%$ of

From the Division of Cardiothoracic Surgery, New England Medical Center, Tufts University School of Medicine, Boston, Mass.

Read at the Seventy-ninth Annual Meeting of The American Association for Thoracic Surgery, New Orleans, La, April 18-21, 1999.

Received for publication April 22, 1999; revisions requested July 16, 1999; revisions received Aug 20, 1999; accepted for publication Sept 21, 1999.

Address for reprints: Kamal R. Khabbaz, MD, Tufts-New England Medical Center, 750 Washington St, NEMC \#266, Boston, MA 02111 (E-mail: k.khabbaz@es.nemc.org).

Copyright (C) 2000 by Mosby, Inc.

$0022-5223 / 2000 \$ 12.00+0 \quad \mathbf{1 2 / 6 / 1 0 3 1 5 5}$ patients $^{1-5}$ and are commonly treated on an outpatient basis with oral antibiotics. However, severe leg-wound complications may prolong a patient's hospital stay ${ }^{1}$ or require readmission for debridement, intravenous antibiotics, and, in some cases, lower extremity revascularization for nonhealing wounds in ischemic limbs. Even when managed as an outpatient, ongoing pain from an open wound, the requirement for dressing changes, and difficulty with ambulation can reduce the patient's quality of life.

Endoscopic vein harvesting has been shown to be effective in decreasing the development of these wound complications. ${ }^{6-9}$

Because of the costs associated with the use of endoscopic equipment, it is important to focus our resources on those patients who will benefit most from this technology. This prospective study was designed to document the prevalence of leg-wound complications, analyze risk factors for its development, and compare the influence of several techniques on the risk of infection. 


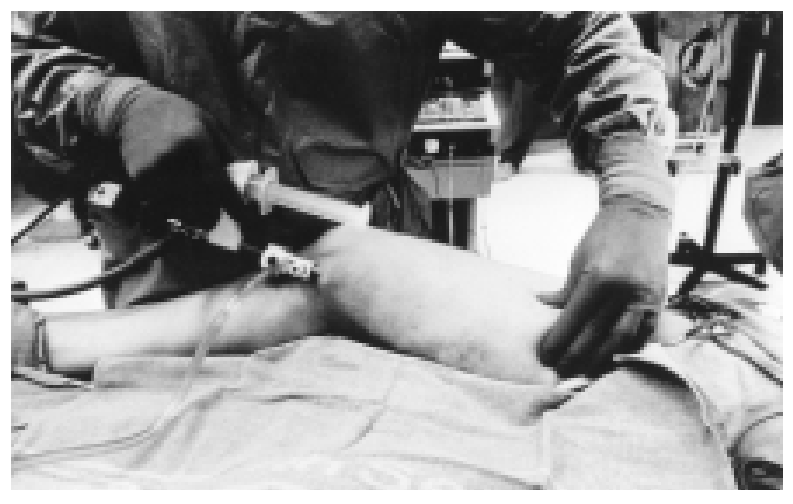

Fig 1. Dissection of the greater saphenous vein in the thigh with the VasoView dissecting device.

It is hypothesized that the use of an endoscopic technique will decrease the morbidity associated with saphenous vein harvesting in patients found to be at high risk for leg-wound complications.

\section{Methods}

From February 1995 to November 1997, 1473 patients undergoing $\mathrm{CABG}$ at New England Medical Center with use of the greater or lesser saphenous veins were followed. Potential risk factors that were analyzed included age, sex, diabetes, obesity (defined as body mass index $>30$ ), peripheral vascular disease, renal failure requiring preoperative or postoperative dialysis, chronic use of steroids, and left ventricular ejection fraction. Variables in surgical technique included the experience level of the individual harvesting the vein, the type of closure (staples vs subcuticular closure), and the creation of a flap during harvesting. Cefazolin was used for antibiotic prophylaxis for 48 hours unless the patient was allergic to penicillin or receiving a prosthetic valve, in which case vancomycin was used. Skin surfaces were shaved the day of surgery and prepped with isopropyl alcohol and 10\% povidone-iodine solutions. Ioban-impregnated adhesive drapes (3M) and a bacteriostatic cardiac drape (Cardiovascular Split Sheet II, Baxter Convertors) were used to cover all exposed surfaces.

The open technique entailed an incision beginning at the ankle made by using a \#10 blade for the skin incision and Metzenbaum scissors, electrocautery, or both for deeper tissues. The entire vein was exposed by means of a continuous incision. Vein branches were ligated proximally with 4-0 silk and clipped distally. Hemostasis was achieved by using electrocautery (Valley Lab Force 40), with energy levels varying from 30 to $45 \mathrm{~W}$. The wound was closed in layers before or during cardiopulmonary bypass by using 1 to 2 layers of running 2-0 Vicryl suture (Ethicon, CT-1). The skin was closed with either staples (Pilling Weck Visistat) or a continuous horizontal mattress subcuticular suture of 3-0 Vicryl (Ethicon, PS2) or Monocryl (Ethicon, PS2). All legs were wrapped with an elastic bandage for 24 hours. Staples were removed on the fifth postoperative day, and adhesive strips
Table I. Grading for leg-wound complications

Mild
$<1 \mathrm{~cm}$ from the wound edge with or without wound separation
Moderate
$<1 \mathrm{~cm}$ from the wound edge with purulent drainage
$>1 \mathrm{~cm}$ from the wound edge with or without wound separation
Severe
$>1 \mathrm{~cm}$ from the wound edge with purulent drainage or
Breakdown of the wound with eschar requiring debridement \pm cellulitis
Location
A: Lower leg
B: Upper leg
C: Entire leg

were applied. If significant lower leg edema was present, the staples were removed 1 week after discharge. The wounds were cleaned with povidone-iodine and covered with a dry sterile dressing daily for 4 days. Wounds were assessed daily in the hospital, 2 weeks after discharge, and, on an outpatient basis, whenever an infection was identified by the patient, referring physician, or visiting nurse. Follow-up was $100 \%$. Infections were graded according to severity and location (Table I).

The bridging technique used four to six 4-cm incisions starting at the ankle, with tunnels created at 7- to 8-cm intervals. An average of 6 incisions was made for an entire vein harvest. For exposure, a headlight source and an army-navy retractor were used. Vein branches were clipped distally and, if exposed, ligated with 4-0 silk. If the tributaries were located in the tunnel, they were clipped distally and ligated with 4-0 silk after the vein had been harvested. Hemostasis and closure was performed in the same fashion, as previously described. The legs were wrapped in an elastic bandage for 48 hours. Wound care was as previously noted.

We subsequently investigated the influence of endoscopic vein harvesting (Fig 1) on the occurrence of leg-wound complications in patients found by statistical analysis to be at highest risk. With the standard open technique, these patients (diabetic, obese, or both types of patients) had a $24 \%$ prevalence of leg-wound complications. From November 1997 to July 1998, we randomized 132 consecutive high-risk patients (diabetic, obese, or both types of patients) alternating between the continuous open technique and endoscopic technique. Sixty-six patients were included in each group. Variables evaluated included the following: time required to complete the harvest and prepare the vein, including number of repairs required; length of vein harvested; and time for leg closure. All procedures were performed by the same 2 physician assistants. The equipment included a VasoView system (Origin Med Systems; Fig 2), a working scope, a Tricam SLIMP camera system, an Endoflator high flow carbon dioxide (Karl Storz Endoscopy America, Inc), a tower monitor, and a monitor suspended across from the operative field. The system, camera, and endoscopes were gas sterilized for every 
Table II. Patient demographics: Open and bridging techniques

\begin{tabular}{|c|c|}
\hline Characteristics & $(n=1473)$ \\
\hline Age (y) & $66 \pm 10.5$ \\
\hline Male sex (n) & 1013 \\
\hline Female sex (n) & 460 \\
\hline Diabetes mellitus (n) & 335 \\
\hline Obese $^{*}(n)$ & 212 \\
\hline PVD (n) & 141 \\
\hline Renal failure $^{\dagger}(\mathrm{n})$ & 42 \\
\hline Flap (n) & 83 \\
\hline Average LVEF (\%) & $45 \pm 13$ \\
\hline Average number of grafts & $3.9 \pm 1$ \\
\hline Days to diagnose infection & $19 \pm 11$ \\
\hline
\end{tabular}

$P V D$, Peripheral vascular disease; $L V E F$, left ventricular ejection fraction.

*Body mass index greater than 30.

'Preoperative or postoperative dialysis.

case. This enabled manipulation of the camera on the field, allowing for rapid changes between endoscopes.

The greater saphenous vein was exposed by means of a 2$\mathrm{cm}$ transverse incision along the medial surface of the knee. The vein was dissected free and surrounded by a vessel loop. Subcutaneous tunnels were created proximally and distally. Branches that were easily identified were clipped and ligated. The endoscopic dissecting device VasoView (Origin Med Systems) was then placed in the distal space. A tunnel was created by blunt dissection along the length of the saphenous vein. After 5 to $10 \mathrm{~cm}$ of blunt dissection, simultaneous insufflation was performed by using carbon dioxide to a pressure of 12 to $15 \mathrm{~mm} \mathrm{Hg}$ through an insufflation port (Uniport). The vein was circumferentially dissected, and the vein tributaries were identified. If the space was narrow after the dissection, a 30-mL balloon at the end of the dissecting devices was inflated to create a working space. A working scope was then placed through the Uniport. Further dissection of adherent tissue was performed by using a $\mathrm{C}$-ring dissector and bipolar scissors. Bipolar scissors were used to ligate the vein tributaries at an energy level of $30 \mathrm{~W}$. Once all tributaries were ligated, a $2-\mathrm{cm}$ incision was made at the ankle. The distal portion of the vein was then removed. The same procedure was repeated for the proximal vein to the groin. The resulting 3 incisions were closed by using 2-0 Vicryl running and 3-0 Vicryl subcuticular sutures. Drains were not used in either the endoscopic or open groups. The leg was then wrapped in an elastic bandage for 48 hours. Wound care was performed as described previously. Pain assessment was performed daily and 2 weeks after discharge on the basis of a scale from 1 to 10 (1-3, mild; 4-6, moderate; and 7-10, severe). Wounds were assessed daily in the hospital, 2 weeks after discharge, and on an outpatient basis whenever an infection was identified by the patient, referring physician, or visiting nurse. Infections were graded according to severity and location (Table I). Follow-up was $100 \%$ in each group.

Statistical analysis was performed with SPSS software. Continuous variables were evaluated by using the Student $t$

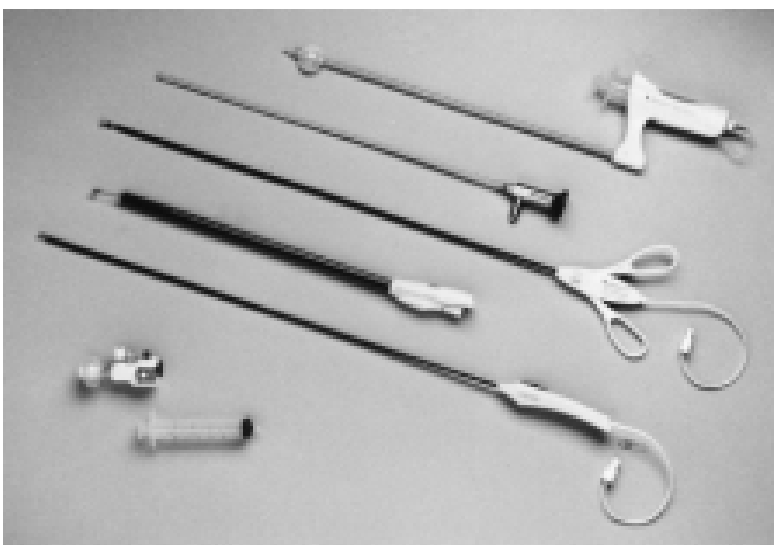

Fig 2. From top to bottom: VasoView dissecting device, 4-mm endoscope, bipolar scissors, working scope with modified Cring dissector, Uniport.

Table III. Risk factors for leg-wound infection: Statistical analysis

\begin{tabular}{lcc}
\hline Variable & $\begin{array}{c}\text { Univariate analysis } \\
(\mathrm{P} \text { value })\end{array}$ & $\begin{array}{c}\text { Multivariate analysis } \\
\text { (P value) }\end{array}$ \\
\hline Age & .7 & .5 \\
Female sex & .04 & .2 \\
Diabetes mellitus $^{*}$ & $<.001$ & .02 \\
Obese $^{*}$ & $<.001$ & .001 \\
PVD & .1 & .5 \\
Renal failure $_{\text {Flap }}$ & .6 & .5 \\
Closure $^{\dagger}$ & .3 & .2 \\
Technique $^{\ddagger}$ & .6 & .8 \\
\hline
\end{tabular}

$P V D$, Peripheral vascular disease.

*Body mass index greater than 30 .

${ }^{\dagger}$ Staples vs subcuticular closure.

*Bridging $(n=150)$ versus open $(n=466)$.

test. Univariate analysis of categorical variables was done by using $\chi^{2}$ analysis. A multiple logistic regression analysis was used to determine which variables were independent risk factors for complications.

\section{Results}

From February 1995 to November 1997, a total of 1473 patients were followed (Table II). The overall prevalence of infection was 9.8\% (145/1473). The mean time to diagnosis was $19.5 \pm 11$ days. Infections were graded according to severity and location (Table I).

By univariate analysis, female sex $(P=.04)$, diabetes $(P=.001)$, and obesity $(P<.001)$ were statistically significant. However, multivariate analysis revealed that only diabetes $(P=.02)$ and obesity $(P=.001)$ were significant independent risk factors, with relative risks of 1.6 and 1.9, respectively (Table III). There was no dif- 


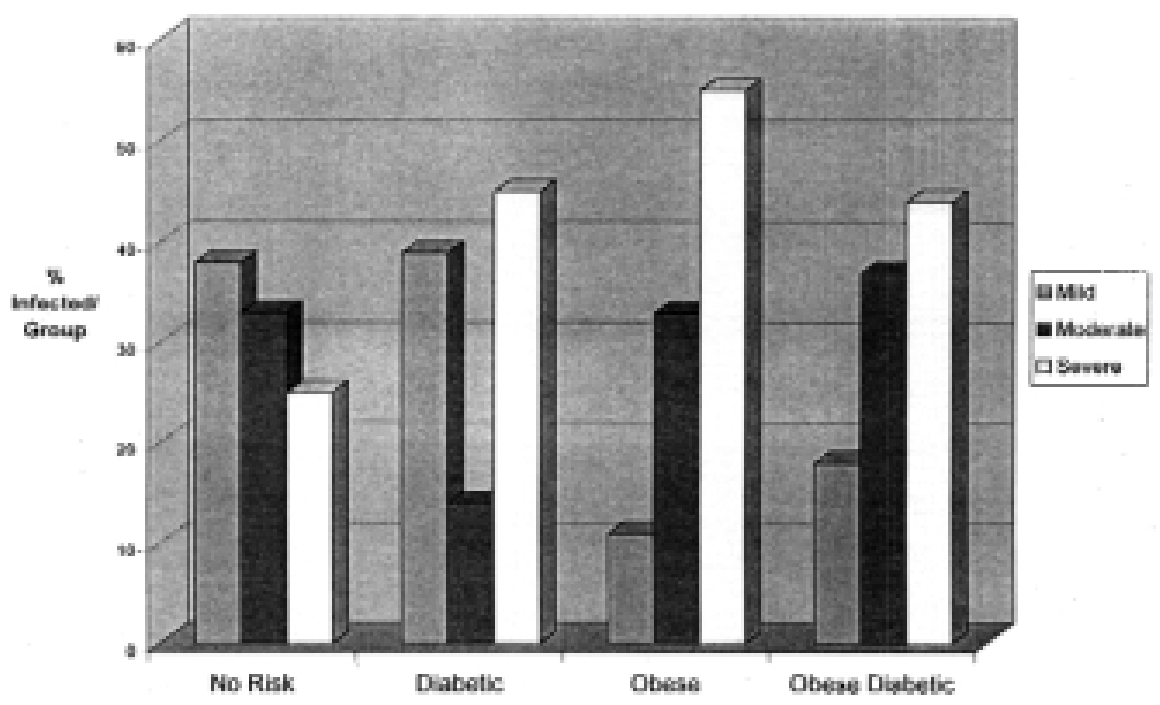

Fig 3. Correlation of risk factors and severity of infection.

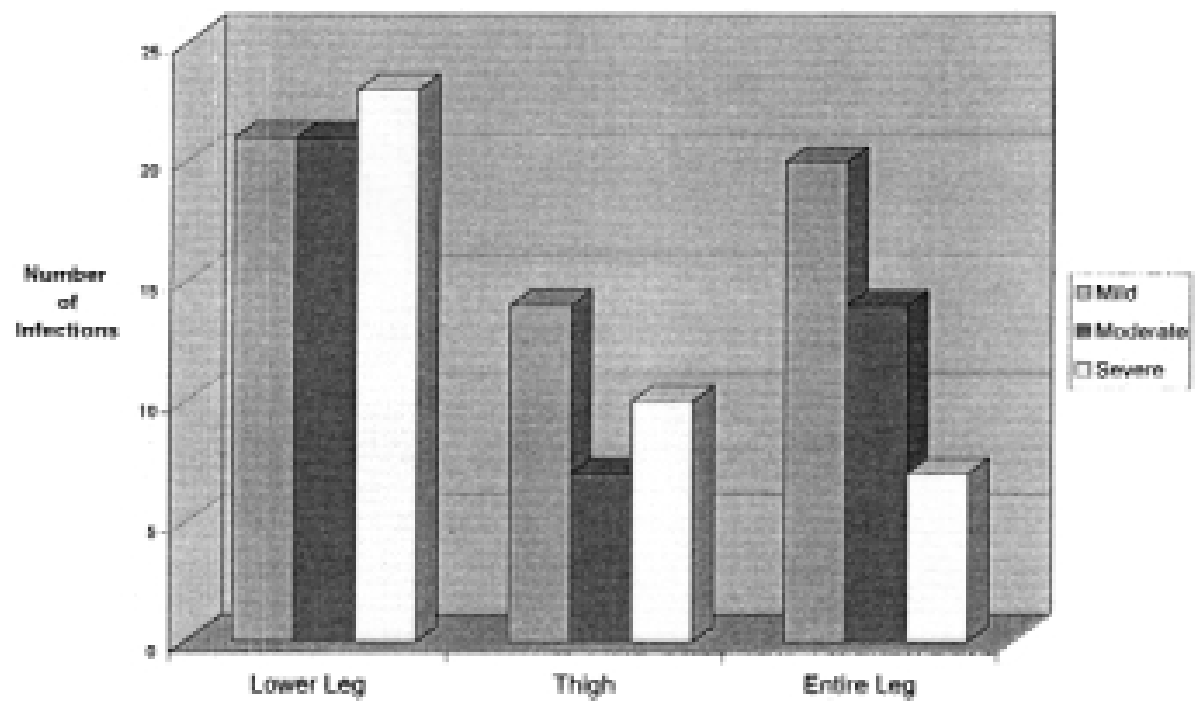

Fig 4. Correlation of severity of infection with its location.

ference in the prevalence of infection comparing subcuticular closure (84/900 [9.3\%]) with staple closure $(61 / 579$ [10.5\%]).

A comparison was made of the continuous and bridging techniques. Demographics for both groups were similar. The prevalence of infection was $6.7 \%(10 / 150)$ for patients undergoing the bridging technique and $6.4 \%$ (30/466) for patients undergoing open harvest. Although the prevalence of infection did not differ, the open technique was associated with more severe infections (30\% moderate and 36\% severe) that involved larger areas of the wound in comparison with the less- invasive bridging technique (60\% moderate and $10 \%$ severe).

The prevalence and severity of infection correlated with the presence of diabetes, obesity, or both. In patients with both factors, the prevalence of wound infection was $24 \%$ with the continuous open technique. Also, of the patients with severe infections, $71 \%$ had one or more significant risk factors (Fig 3). The majority of leg-wound complications occurred in the lower leg, where infections tended to be more severe when compared with the upper or entire leg (Fig 4). Of the 145 patients with leg-wound complications, 17 were 
readmitted with severe complications that required intravenous antibiotics and, in most cases, extensive debridement. Two patients had severe peripheral vascular disease that required revascularization. Of these 17 patients, $71 \%$ had one or both of these risk factors, and their average length of hospital stay was 6 days.

From December 1997 to July 1998, 66 high-risk patients undergoing continuous open saphenectomy were compared with 66 high-risk patients undergoing endoscopic vein harvesting by using the VasoView (Origin Med Systems) system. The 2 groups were demographically similar. The prevalence of infection was $4.5 \%$ (3/66) for patients undergoing the endoscopic technique and $20 \%(13 / 66)$ for patients undergoing open harvest $(P=.01)$. Of the 13 infections in the open group, 2 were minor, 8 were moderate, and 3 were severe. Of the 3 infections in the endoscopic group, 1 was minor and 2 were moderate. No patient infections in either group required hospitalization or intravenous antibiotics.

When compared with the standard open technique, endoscopic harvest time was twice as long $(65 \pm 28$ minutes vs $33 \pm 20$ minutes, $P<.001$ ), although the length of vein harvested was similar in both groups. A range of 0 to 10 repairs per harvest was noted, with a median of 1 and a mean of 2.8 in the endoscopic group compared with a range of 0 to 5 repairs per harvest and with a median of 0 and a mean of 0.6 in the continuous open group $(P<.001$; Table IV). Patients treated with the open technique had more severe infections involving larger areas of the wound. The average daily pain score was 2 on a scale from 1 to 10 through discharge and on follow-up. There was no difference in ability to ambulate or in length of stay. Seven patients in the endoscopic group required partial conversion to open on the same or contralateral side. More vein was needed in 3 patients, the vein was too superficial in the lower leg of 1 patient, excessive bleeding occurred after a branch avulsion in 1 patient, 1 patient became hemodynamically unstable necessitating rapid harvest, and 1 patient was converted because of technical difficulties. Another 3 patients required conversion to complete open technique: 2 patients had poor vein quality, and the vein could not be identified in one morbidly obese patient.

\section{Discussion}

Leg wound complications after CABG are an underappreciated source of patient morbidity. They may prolong the hospital stay or necessitate readmission for intravenous antibiotics and debridement, both of which will increase hospital costs. They may also increase
Table IV. Endoscopic versus open technique: Statistical analysis

\begin{tabular}{lccc}
\hline & $\begin{array}{c}\text { Open } \\
\text { technique } \\
(n=66)\end{array}$ & $\begin{array}{c}\text { Endoscopic } \\
\text { technique } \\
(n=66)\end{array}$ & P value \\
\hline Characteristics & $67.5 \pm 9.5$ & $65.7 \pm 9.2$ & $>.2$ \\
Age (y) & $35 / 31$ & $41 / 25$ & .04 \\
Sex (M/F) & $46(69)$ & $40(63)$ & $>.2$ \\
Diabetes mellitus, n (\%) & $50(77)$ & $51(80)$ & $>.2$ \\
Obese, n (\%) & $33 \pm 20$ & $72 \pm 28$ & $<.001$ \\
Harvest time (min) & $34 \pm 15.4$ & $12 \pm 6.4$ & $<.001$ \\
Closure time (min) & $44 \pm 16.7$ & $46 \pm 16.7$ & $>.2$ \\
Vein length (cm) & $0.6 \pm 1.1$ & $2.5 \pm 2.5$ & $<.001$ \\
No. of repairs & $3.9 \pm 1$ & $3.9 \pm 1$ & $>.2$ \\
No. of grafts & $8 \pm 4$ & $7.5 \pm 5$ & $>.2$ \\
Length of stay (d) & $13(20)$ & $3(4.5)$ & $<.001$ \\
Infection, $\mathrm{n}(\%)$ & & & \\
\hline
\end{tabular}

*Includes vein preparation time.

outpatient costs associated with oral antibiotics and visiting nurses. Perhaps most importantly, they affect the patient's quality of life by producing persistent pain, discomfort, and difficulty with ambulation and frequently necessitating lengthy and painful dressing changes and multiple outpatient visits for debridement.

The prevalence of infection varies widely in the literature (from 1\%-20\%), depending to some degree on the definition of leg-wound complications, as well as the intensity of follow-up. ${ }^{1-5}$ The Society of Thoracic Surgeons National Cardiac Database in 1998 noted a prevalence of leg-wound infection of only $1.5 \%$, but observation may be limited to the hospital stay. ${ }^{10}$ Thus this may significantly underestimate the true prevalence of infections because our study, as well as those of others, have shown that the mean time to diagnosis is about 2 to 3 weeks after surgery. ${ }^{4}$ The morbidity associated with this problem, from a quality-of-care standpoint, as well as a financial standpoint, justifies the investigation of alternative techniques to potentially reduce the risk of infection in high-risk patients.

The use of smaller incisions, including bridging techniques with various devices ${ }^{11-14}$ and a wide range of endoscopic devices now available, has enhanced the potential for decreasing morbidity from leg-wound complications. ${ }^{6-9,} 15$ We hypothesized that a bridging technique would maintain improved vascularity to superficial tissues and reduce the development of complications. We did find a significant difference in the severity of leg-wound complications, but this technique was technically difficult, often producing vein trauma and branch avulsion from overmanipulation and dissection. In addition, significant ecchymoses and hematomas commonly formed within the tunnels. 
Satisfactory instrumentation for this technique is still being developed and investigated.

The use of endoscopic vein harvesting has significantly decreased postoperative pain, improved mobility, decreased length of stay, and reduced the occurrence of leg-wound complications. ${ }^{6-9}$ Although there was no significant difference in length of stay and postoperative pain in our study, we have demonstrated a significant decrease in the frequency and severity of legwound complications in high-risk patients by using endoscopic vein harvesting.

Some of the drawbacks to endoscopic vein harvesting include harvest and vein preparation and potential trauma to the vein during harvesting. Cable and colleagues ${ }^{16}$ reported no significant endothelial disruption with endoscopic harvesting. In our series we averaged 2.8 repairs per vein, mainly related to small vein branch avulsions. With no previous endoscopic experience, the learning curve using the Origin system took approximately 5 to 10 cases. In our series the first 10 cases averaged $94 \pm 43$ minutes, whereas the last 53 cases averaged $60 \pm 20$ minutes (Table IV). The conversion rate in our study was $4.5 \%$, with 3 patients requiring complete conversion to the open technique. Seven patients underwent a hybrid combination of the endoscopic and open techniques. Conversions were not related to the learning curve but were more common in patients with minimal subcutaneous tissue and those with thin fragile veins, in whom the shearing force exerted by the endoscope resulted in damage to the vein and its tributaries. Vein quality and size were also difficult to assess by using the endoscope because the vein was not directly visualized, and it could not be palpated except at the knee. With the open technique, the vein could be dilated after a small amount was harvested to assess its size and quality.

Although endoscopic vein harvesting may minimize leg-wound complications, reduce pain, and improve patient satisfaction, it remains controversial whether it is a cost-effective strategy. Disposables for the VasoView system range from $\$ 450$ to $\$ 550$ per case, to which must be added the initial startup cost of video, monitors, and cameras, which is approximately $\$ 45,000$. The projected cost of using endoscopic vein harvesting in our high-risk population over the past 2.5 years was $\$ 273,900$ (498 patients $\times \$ 550$ ). The total direct cost to our hospital for readmission for legwound complications in the high-risk population (17 readmitted patients) was $\$ 85,079.00$. This amount divided over the entire high-risk group $(n=498)$ translates to a cost of $\$ 171.00$ per patient per readmission. Using this simple analysis, we are unable to demon- strate any financial benefit to the use of this technique, even in our high-risk population. However, other factors, including patient satisfaction, postoperative pain, long-term morbidity, and the cost of outpatient care, may make implementation of a program of minimally invasive vein harvesting feasible.

\section{Conclusion}

We have shown that the use of endoscopic vein harvesting has been of benefit in reducing the prevalence of leg-wound infections in high-risk patients undergoing saphenous vein harvesting for CABG. Therefore we recommend its use in diabetic, obese, or both types of patients. Although patients with peripheral vascular disease did not have a significantly increased prevalence of complications overall, infections that developed in these patients were severe. Therefore this technique would also be applicable to that patient population. For patients at low risk for wound infection, justification for use of an endoscopic approach would be purely cosmetic because the added cost was not associated with any difference in leg pain or length of stay. However, it is possible that the patient's perception of "lesser surgery" and improved mobility related to less leg discomfort could improve the patient's quality of life.

\section{REFERENCES}

1. Delaria GA, Hunter JA, Goldin MD, Serry C, Javid H, Najafi H. Leg wound complications associated with coronary revascularization. J Thorac Cardiovasc Surg 1981;81:403-7.

2. Utley JR, Thomason ME, Wallace DJ. Preoperative correlates of impaired wound healing after saphenous vein excision. J Thorac Cardiovasc Surg 1989;98:47-9.

3. Farrington M, Webster M, Fenn A, Phillips I. Study of cardiothoracic wound infection at St. Thomas hospital. Br J Surg 1985;72:759-62.

4. Slaughter MS, Olson MM, Lee JT, Ward HB. A fifteen year wound surveillance study after coronary artery bypass. Ann Thorac Surg 1993;56:1063-8.

5. Wilson AP, Livesey SA, Treasure T, Gruneberg RN, Sturridge MF. Factors predisposing to wound infection in cardiac surgery. A prospective study of 517 patients. Eur J Cardiothorac Surg 1987;1:158-64.

6. Davis Z, Jacobs HK, Zhang M, Thomas C, Castellanos Y. Endoscopic vein harvesting for coronary artery bypass grafting: technique and outcomes. J Thorac Cardiovasc Surg 1998;116: 228-34.

7. Allen KB, Griffith GL, Heimansohn DA, et al. Endoscopic versus traditional saphenous vein harvesting: a prospective, randomized trial. Ann Thorac Surg 1998;66:26-32.

8. Pagni S, Ulfe EA, Montgomery WD, et al. Clinical experience with the video-assisted saphenectomy procedure for coronary bypass operations. Ann Thorac Surg 1998;66:1626-31.

9. Morris RJ, Butler MT, Samuels LE. Minimally invasive saphenous vein harvesting. Ann Thorac Surg 1998;66:1026-8. 
10. 1998. The Society of Thoracic Surgeons. www.STS.ORG, STS National Database, Incidence of complications and operative morbidity summaries, CABG, CABG + AVR, CABG + MVR.

11. Tevaearai HT, Mueller XM, von Segesser LK. Minimally invasive harvest of the saphenous vein for coronary artey bypass grafting. Ann Thorac Surg 1997;63:119-21.

12. Tran HM, Paterson HS, Meldrum-Hanna W, Chard RB. Tunnelling versus open harvest technique in obtaining venous conduits for coronary bypass surgery. Eur J Cardiothorac Surg 1998; $14: 602-6$

13. Meldrum-Hanna W, Ross D, Johnson D, Deal C. An improved technique for long saphenous vein harvesting for coronary revascularization. Ann Thorac Surg 1986;42:90-2.

14. Newman NV, Lammle WG. Minimally invasive vein harvesting: new techniques with old tools. Ann Thorac Surg 1999;67:571-2.

15. Cable DG, Dearani JA. Endoscopic saphenous vein harvesting: minimally invasive video-assisted saphenectomy. Ann Thorac Surg 1997;64:1183-5.

16. Cable DG, Dearani JA, Pfeifer EA, Daly RC, Schaff HV. Minimally invasive saphenous vein harvesting: endothelial integrity and early clinical results. Ann Thorac Surg 1998;66:139-43.

\section{Discussion}

Dr Robert J. March (Chicago, Ill). Endoscopic vein harvesting techniques strive to reduce wound complications, patient discomfort, and rehabilitation time. DeLaria first called attention to the high prevalence of saphenous vein harvest wound infections in 1981, and Lumdsen in 1994 reported a new method of harvesting vein by using subcutaneous retractors. The technique continues to evolve.

Criticisms of endoscopic vein harvest include increased harvest time, additional expense, and a potential for vein trauma. This study showed no difference between continuous and bridged incisions on retrospective analysis, as indicated in the manuscript; multivariate analysis, however, suggested the presence of diabetes and obesity as predictors of harvest wound infection. Then, in a randomized cohort of patients in this high risk subgroup, endoscopic vein harvest was associated with a prevalence of wound infection of $4.5 \%$ for the endoscopic group, with infections generally being mild to moderate, versus a $20 \%$ prevalence for the open technique group, with infections being moderate to severe. The drawbacks for the endoscopic group, however, included a doubling of the harvest time and a tripling of the need for vein repair. The conversion rate to the open technique was $4.5 \%$, and additional incisions were required in another $10 \%$.

I have the following questions.

What was the prevalence of wound infection in patients with diabetes and obesity in your retrospective analysis in terms of the bridging technique? You chose the continuous technique because no difference was alluded to. The bridging technique, with its lower equipment costs and apparent clinical benefit in other series, may have provided for a more fair comparison to the endoscopic group.

Operative use of carbon dioxide has been associated with hypercapnia, acidosis, and hypothermia. Did you observe any of these or other complications with the carbon dioxide insufflation?
Other studies suggest that endoscopic harvest does not increase endothelial damage. Did you perform any histologic studies on your patients?

Your study focused on wound infection, but were there any differences between the 2 techniques in terms of hematomas, saphenous neuralgia, or lymphedema?

Although your study did not show any in-hospital cost savings, we might expect a cost savings for this high-risk group in terms of resource use after discharge, as well as a quicker return to work, things that are more difficult to quantify.

With increasing use of arterial grafts, our practice has isolated the use of endoscopic vein harvest to the thigh with a single incision, keeping the wound away from the flexion point at the knee. Some of your photographs indicate a close approximation of your incision to this flexion point. Could this have accounted for the similar amount of discomfort reported by the endoscopic group compared with the group treated with the open technique? The pain scales also are somewhat subjective. Did you look at narcotic use as well?

Dr Allen S. Hudspeth (Winston-Salem, NC). It is interesting to me that neither the presenter nor the discussant mentioned anything about the heart. When we first started out to put more blood into the myocardium with these operations, and certainly the conduits are critical, we started initially taking veins out through little keyholes, and we found that we damaged the veins.

I would be very interested and would believe these improvements if we had evidence that these grafts were just as good or better than the ones we have had. Some people have said you can either mutilate the leg or mutilate the vein. I wonder if you might comment on what the results of these vein grafts were.

Dr Keith B. Allen (Indianapolis, Ind). Your study mirrors the prospective randomized study that we presented at last year's meeting of the Society of Thoracic Surgeons and was published last year in The Annals of Thoracic Surgery. Our results are exceedingly similar. Although one can debate which endoscopic technique to use, I applaud you in evaluating this particular technology and encourage surgeons to use this technique. Saphenectomy wound complications are grossly underestimated in coronary artery surgery and deserve more attention.

We have recently submitted a histologic analysis in 150 patients that demonstrated no difference in endothelial, medial, or adventitial trauma, and I would strongly suggest that this is a very good technique.

Mr Carpino. Dr March, I appreciate your comments. Referring to the prevalence of infection with the diabetic and obese patients with the bridging technique, I do not have those numbers at hand. Today I wanted to specifically focus on the comparison of open versus endoscopic techniques. We did evaluate the bridging technique as part of this study.

The group of patients that had the bridging technique did have more diabetic and obese patients compared with the open group. Open versus bridging were not exactly demographically similar; however, as you noted from my manuscript, there is no difference in prevalence of infection 
between the 2 groups. The severity of infections with patients who have undergone the bridging technique was much less than the patients who had the open technique.

We have noticed no problems with $\mathrm{CO}_{2}$ retention, although I was speaking with some people yesterday, and they had reported one incident of high $\mathrm{CO}_{2}$ during a vein harvest that the anesthesiologist had to correct for, with a $\mathrm{CO}_{2}$ level as high as 64. But we had no problems with elevated $\mathrm{CO}_{2}$ during our procedures.

Histologic evaluation has been touched on. We personally did not do studies, but Dr Cable did a study of the histologic evaluation of veins after endoscopic harvesting, I believe it was a few years back, which showed no intimal injury, and as was discussed by Dr Allen, that seems pretty consistent. However, I would say that if you are going to do an evaluation, there are intimal injuries from smaller avulsed branches requiring 7-0 repairs, and there has got to be a potential for thrombosis or early stenosis. We had no returns for angina or perioperative myocardial infarctions in our groups, and I believe that is pretty similar for most of the other people who have published on endoscopic vein harvesting.

A question on difference of hematomas and edema: We did not follow edema very well in our study. It has been reported in a few other studies regarding edema, and there seemed to be no difference in previous studies.

As far as hematomas, we did see a fair amount of hematomas in the thigh in the patients who had the endoscopic technique performed. We keep the legs wrapped in Ace bandages for 48 hours, hoping to decrease the prevalence of hematomas. We even tried putting drains in, but that did not seem to make a difference. This did not seem to adversely affect the patients' recovery, did not cause infection, seemed to resolve quickly on its own, and by 2 -week follow-up, most of the patients had resolution of these hematomas.

I did not document an increased use of narcotics with patients who had the open technique compared with the endoscopic technique.

\section{Authoritative}

The Journal of Thoracic and Cardiovascular Surgery is the most frequently cited thoracic/cardiovascular surgery journal in the Science Citation Index. An article in JTCVS is sited on average almost twice as often as those in the closest cardiothoracic journal. 